\title{
Evaluation of fiber-optic sensing performance for embedded thermal monitoring of electric machinery wound components
}

DOI:

10.1109/MECO.2016.7525706

Link to publication record in Manchester Research Explorer

Citation for published version (APA):

Mohammed, A., \& Durovic, S. (2016). Evaluation of fiber-optic sensing performance for embedded thermal monitoring of electric machinery wound components. In 20165 th Mediterranean Conference on Embedded Computing (MECO) (pp. 72-76). IEEE. https://doi.org/10.1109/MECO.2016.7525706

Published in:

2016 5th Mediterranean Conference on Embedded Computing (MECO)

\section{Citing this paper}

Please note that where the full-text provided on Manchester Research Explorer is the Author Accepted Manuscript or Proof version this may differ from the final Published version. If citing, it is advised that you check and use the publisher's definitive version.

\section{General rights}

Copyright and moral rights for the publications made accessible in the Research Explorer are retained by the authors and/or other copyright owners and it is a condition of accessing publications that users recognise and abide by the legal requirements associated with these rights.

\section{Takedown policy}

If you believe that this document breaches copyright please refer to the University of Manchester's Takedown Procedures [http://man.ac.uk/04Y6Bo] or contact uml.scholarlycommunications@manchester.ac.uk providing relevant details, so we can investigate your claim.

\section{OPEN ACCESS}




\title{
Evaluation of Fiber-optic Sensing Performance for Embedded Thermal Monitoring of Electric Machinery Wound Components
}

\author{
Anees Mohammad, Siniša Djurović \\ Power and Energy Division, School of Electrical and Electronic Engineering \\ University of Manchester \\ Manchester, UK \\ Anees.Mohammed@postgrad.manchester.ac.uk, Sinisa.Djurovic@manchester.ac.uk
}

\begin{abstract}
This paper investigates the thermal monitoring performance potential of fibre-optic (FO) thermal sensors embedded into the structure of random wound coils. The implications of FO sensor packaging and installation procedure on thermal monitoring performance are assessed on a prototype coil in a series of laboratory experiments in a controlled thermal ambient. It is shown that, while the procedure of embedding the FO sensor into the coil structure alters its operational characteristics to an extent, the resulting in-situ hot spot thermal monitoring provides a reliable output when benchmarked with conventional thermocouple measurements.
\end{abstract}

Keywords- Fibre Bragg grating sensors; thermal monitoring; electrical windings; winding temperature; embedded sensing.

\section{INTRODUCTION}

Electric machines are an essential component of modern industrial systems. The awareness of the operational integrity of on-line electric machinery is of significant interest in order to ensure its appropriate functioning [1]. This is normally achieved through continuous monitoring of the vital machine operational parameters, including electrical, mechanical and thermal signals, to extract indices containing information on the device operating status [1-5]. Thermal monitoring of motor windings is of particular interest in this respect $[5,6]$, as severe winding insulation breakdown and the consequent significant thermal stress have been reported to contribute to as much as $\approx 30-40 \%$ of all failures in conventional induction machinery [7]. Achieving accurate monitoring of the winding hot spot temperature is therefore key in enabling effective machine thermal protection and lifetime extension by prevention of undetected and prolonged thermal overloads.

The conventional practice in monitoring the thermal conditions of machine wound components is largely founded on utilisation of thermocouple (TC) or resistance temperature detector (RTD) based embedded sensing solutions; these however impose considerable challenges with regards the attainable location of embedded thermal sensing, due to the inherent use of electrically conductive material in their structure as well as their susceptibility to EMI effects [6]. An attractive alternative is provided by the recent advances in fibre-optic (FO) sensing which have the potential to deliver effective solutions for embedded thermal sensing in wound components. The FO sensors' inherent advantages of EMI immunity, robustness and size make them a strong candidate for enabling operative solutions for embedded sensing in electric machinery [8]. The potential of Fibre-Bragg grating (FBG) sensors in particular has already been attention in a variety of electric machinery monitoring applications, ranging from frame vibration sensing to stator core and coil surface thermal monitoring [9-13].

This work examines the thermal monitoring performance of an FBG sensor embedded in the centre of a prototype coil wound of class $\mathrm{F}$ insulated copper wire, as is typical of most conventional electric machines [6]. The paper reports the results of an experimental study undertaken on a prototype motorette exposed to a range of steady-state and transient thermal conditions inside a controlled thermal chamber. The FBG thermal sensor measurements are benchmarked against those obtained from a conventional TC sensor placed in close proximity. The underlying aim of this work is to provide an insight into the performance implications of the installation procedure of a wound coil embedded FBG thermal sensor and an assessment of its in-situ sensing performance, as a precursor to enabling further development of embedded sensing applications within operational devices.

\section{FBG THERMAL SENSING PRINCIPLES}

FBGs are the periodic imprints made longitudinally on the optical fibre core to cause its refractive index to manifest a periodic modulation when exposed to an interference pattern of the ultraviolet laser light [14]. The wavelengths reflected by the FBG structure will change with the variation in the temperature and strain it is exposed to, thus enabling the grated fibre to be utilised as a thermal or a mechanical sensor with appropriate design. The FBG centre wavelength can be defined by [15]:

$$
\lambda_{\mathrm{B}}=2 \Lambda n_{\text {eff }}
$$

Where: $\lambda_{\mathrm{B}}$ is the Bragg wavelength, $n_{\text {eff }}$ is the effective fibre core refractive index and $\Lambda$ is the grating period, i.e. the spacing between the gratings. A change in the fibre temperature and/or strain will result in a change of $n_{\text {eff }}$ and $\Lambda$ and consequently in a shift in the reflected wavelength. The relative rate of change of the reflected FBG centre wavelength can be defined in terms of the acting temperature and strain excitation by [14]:

$\Delta \lambda_{\mathrm{B}}=\overbrace{2\left(\Lambda \frac{d n_{e f f}}{d \varepsilon}+n_{\text {ef }} \frac{d \Lambda}{d \varepsilon}\right) \Delta \varepsilon}^{A}+\overbrace{2\left(\Lambda \frac{d n_{e f f}}{d T}+n_{\text {ef }} \frac{d \Lambda}{d T}\right) \Delta T}^{B}$ 
Where: $\varepsilon$ represents strain and $\mathrm{T}$ represents temperature. The term A in (2) signifies the FBG wavelength shift caused by the elastic-optic effect due to strain the term $B$ on the other hand describes the temperature change induced wavelength shift that originates from the thermo-optic and thermal expansion effects [14]. The reflected wavelength shift due to a temperature change can therefore be expressed in terms of the fibre thermal characteristics as [16]:

$$
\Delta \lambda_{\mathrm{B}}=\lambda_{\mathrm{B}}(\alpha+\xi) \Delta T,
$$

Where: $\alpha$ is the fibre thermal expansion coefficient $\left(\approx 0.55 \times 10_{-6} / \mathrm{K}\right)$ and $\xi$ is the fibre thermo-optic coefficient $\left(\approx 6.67 \times 10^{-6} / \mathrm{K}\right)$ [14]. Hence, for a standard FBG with a centre wavelength of $1550 \mathrm{~nm}$ operating at ambient temperature, the fibre thermal sensitivity can be evaluated to be $\approx 11 \mathrm{pm} / \mathrm{K}$.

\section{EXPERIMENTAL TEST SYSTEM}

The target application in this work is thermal sensing embedded in a coil of an electric machine and hence EMI capability is one of the desirable features of the FO sensing element. Another significant design constraint is imposed by the requirement for coil hot spot temperature sensing, meaning that the thermal sensor needs to be located in the centre of the coil structure, implanted between individual coil conductors; in addition, the sensing element also needs to be rated to withstand the operating temperature experienced by windings in conventional class F insulated electric machinery. The bare sensing fibre is fragile and cannot be effectively inserted or wound into the coil architecture due to installation constraints imposed by the coil geometry and structure and the associated mechanical stress. For this purpose the thermal sensing fibre requires appropriate packaging to protect the FBG and isolate it from the external mechanical stress. To this end, Polyetheretherketon (PEEK) tubing is utilised in this study to package the FBG sensing head due to its inherent dielectric and mechanical strength and thermal properties that are a good fit for the operating environment found in conventional electrical machinery. Fig. 1 shows the schematic diagram and a photograph of the packaged sensing element. The total length of the FO probe is $1 \mathrm{~m}$ with the sensing region length of $5 \mathrm{~cm}$ determined by the span of the PEEK tubing housing the FBG sensing head; the sensing fibre is kept loose inside PEEK tubing. A standard FBG in a germanium-doped silica fibre double coated with polyimide is used in this work.
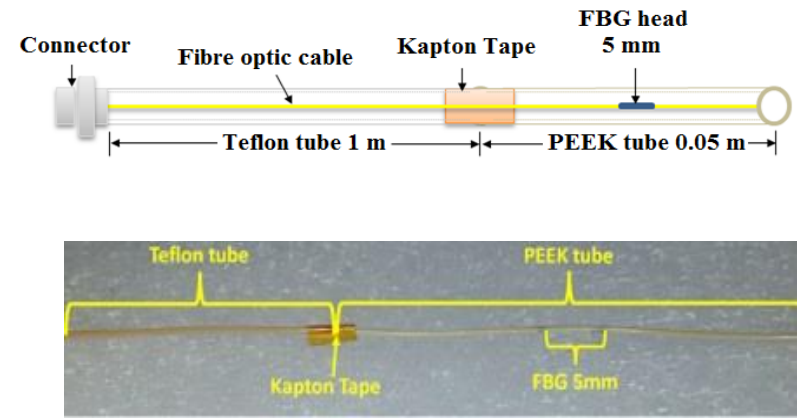

Figure 1. FBG thermal sensor design: diagram (top) and photograph (bottom)
The utilised FBG head length is $5 \mathrm{~mm}$, its bandwidth is $0.374 \mathrm{~nm}$ and its reflectivity $88.11 \%$. The FBG is packaged in peek tubing with the inner diameter of $0.6 \mathrm{~mm}$ and the outer diameter of $0.8 \mathrm{~mm}$ for compatibility with the $0.5 \mathrm{~mm}$ diameter of the investigated motorette design's copper wire. PEEK has a thermal conductivity of $0.173 \mathrm{w} / \mathrm{m} . \mathrm{K}$ and can withstand temperatures up to $\approx 200^{\circ} \mathrm{C}$. The remainder of the optic cable is tubed in Teflon for protective purposes. The sensor package is embedded in the centre of a prototype motorette as shown in Fig.2. The motorette consists of a total of 80 turns of class $F$ enamelled copper wire and is purpose wound on a winding machine. In order to position the thermal sensing package in the coil centre, 40 turns were wound first before placing the FBG package in the centre of the coil and completing the winding of the remaining 40 turns. This procedure enabled the sensing package to be situated in the close proximity to the motorette centre and monitor its thermal hot spot. In order to enable the FBG sensor performance benchmarking against that of a known thermal sensing technology a TC (type K) was placed next to the FBG package during the winding process, as illustrated in Fig. 2b. The tested motorette is designed based on IEEE standard procedure for evaluation of systems of insulating materials for random-wound $\mathrm{AC}$ electric machinery [17]. The test coil is wound on and kept in a support frame shown in Fig. 2a for the purpose of experimental work. The test coil was braced with Kapton tape in places to provide further mechanical support.

The experiment setup is illustrated in Fig.3. The FBG sensor is illuminated by a commercial SmartScan interrogator system enabling dynamic measurement of FBG sensor's wavelength [18]. The TC output is conditioned by an NI 9205 $D A Q$ interfaced with a personal computer executing an appropriate LabVIEW VI. For floating measurements a resistance circuit has been built that includes a Platinum resistance temperature detector (PT100) for cold junction temperature compensation. The prototype motorette with an embedded thermal sensor was placed inside a controlled thermal chamber in the experiments. The chamber was used to apply steady-state and transient thermal stress on the test motorette to evaluate the sensing performance of the embedded FBG sensing system.

\section{RESULTS AND DISCUSSION}

This section reports the results of tests undertaken on the motorette embedded packaged FBG sensor with a view to providing an assessment of its operational characteristics and how these may be affected by the process of sensor installation into a wound coil structure. The temperature sensitivity and linearity of the packaged FBG sensor within the motorette were calibrated in thermal chamber tests in the temperature range from $\approx 20$ to $\approx 160{ }^{\circ} \mathrm{C}$, to match the thermal rating of the examined class $\mathrm{F}$ insulated coil. For this purpose temperature cycling is regulated by the chamber controller to follow a rising sequence of $\approx 20^{\circ} \mathrm{C}$ steps; the temperature was held constant at each thermal step for 1000 secs before the measurements were taken to ensure the thermal equilibrium is achieved. 


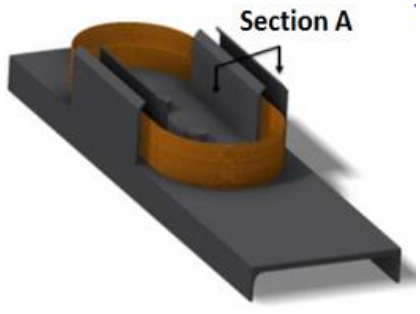

a. Test structure

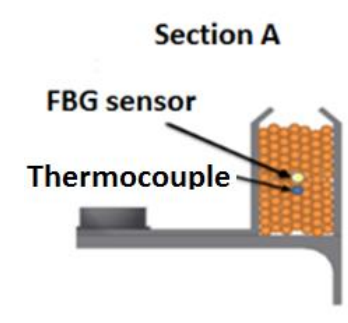

b. Cross-section
Figure 2. Motorette structure (left) showing embedded sensor position (right)

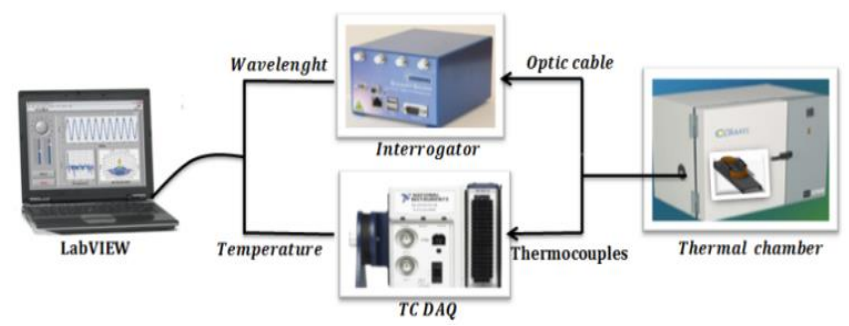

Figure 3. Schematic diagram of the thermal experiment setup

The FBG wavelength and the chamber temperature values were recorded at each assessed thermal equilibrium in the investigated temperature range. For the purpose of comparative analysis an identical calibration procedure was performed on the free FBG head before packaging, i.e. on the bare grated fibre outside the motorette structure. The calibration tests results are shown in Fig. 4. The data indicate a reasonable linearity of the coil embedded packaged FBG sensor, (FBGPeek trace in Fig. 4), with the measured correlation coefficient value higher than $\approx 0.99902$. Furthermore the measured average temperature sensitivity coefficient, $k_{T}$, of a free FBG, (FBG trace in Fig. 4 ), is $\approx 10.78 \mathrm{pm} /{ }^{\circ} \mathrm{C}$, while that of a packaged $\mathrm{FBG}$ sensor is $\approx 10.88 \mathrm{pm} /{ }^{\circ} \mathrm{C}$. These results suggest that PEEK packaging has a negligible effect on the embedded sensor's temperature sensitivity.

A detailed assessment of the implications of embedding the packaged sensor into a motorette coil on its sensing performance is undertaken next. The rated wavelength measurement accuracy of the utilised commercial interrogator is $1 \mathrm{pm}$ resulting in a thermal measurement resolution of $\approx 0.11^{\circ} \mathrm{C}$ for the examined packaged sensor. The range of the Bragg wavelength shift for the packaged FBG sensor embedded in the motorette and the external free FBG sensor were identified from extreme measurements in the investigated temperature range, i.e. from measurements at ambient temperature of $\approx 20^{\circ} \mathrm{C}$ and those taken at $\approx 160^{\circ} \mathrm{C}$. The results report a closely similar range of wavelength shift of $1.512 \mathrm{~nm}$ and $1.498 \mathrm{~nm}$, respectively. It should be noted that the procedure of embedding the packaged FBG sensor within the motorette structure results in an unavoidable mechanical stress on the embedded sensor structure. This is reflected by an inherent Bragg wavelength offset, $\Delta \lambda_{B}$, as illustrated by the measured wavelength reflection spectrum for the embedded, $\lambda_{\mathrm{B} 2}$, and the free, $\lambda_{\mathrm{B} 1}, \mathrm{FBG}$ at ambient temperature shown in Fig. 5a. The measurements clearly indicate an offset of 0.035 $\mathrm{nm}$ between the free and the coil embedded sensor. While the observed offset does not significantly affect the measured wavelength shift range for the examined thermal conditions, its implications on the sensor thermal sensitivity need to be separately assessed.

The influence of the installation induced reflected wavelength offset on the packaged sensor's performance is examined by comparison of the average temperature sensitivity measured in thermal tests on the embedded and the free sensor shown in Fig. 5b. The embedded packaged sensor is seen to manifest a closely similar $\mathrm{pm} /{ }^{\circ} \mathrm{C}$ profile to that of a free FBG in the examined temperature range. It can be observed that the FBG temperature measurement sensitivity increases with the sensed temperature increase from a value lower than $\approx 10$ $\mathrm{pm} /{ }^{\circ} \mathrm{C}$ to $\approx 12 \mathrm{pm} /{ }^{\circ} \mathrm{C}$; this behaviour is typical for FBG sensors due to the nonlinearity of the thermo-optic coefficient of the optic fibre [19]. More importantly, the obtained results suggest that the procedure of embedding a packaged FBG sensor within a wound coil structure does not significantly modulate this behaviour. In addition, the reported measured sensitivity profile of the embedded sensor is approximately constant and uniform in the temperature range of $\approx 70^{\circ} \mathrm{C}$ to $\approx 130^{\circ} \mathrm{C}$; this can enhance the sensing accuracy in this thermal range, which conveniently matches the thermal operation limits for windings in most conventional electric machinery designs.

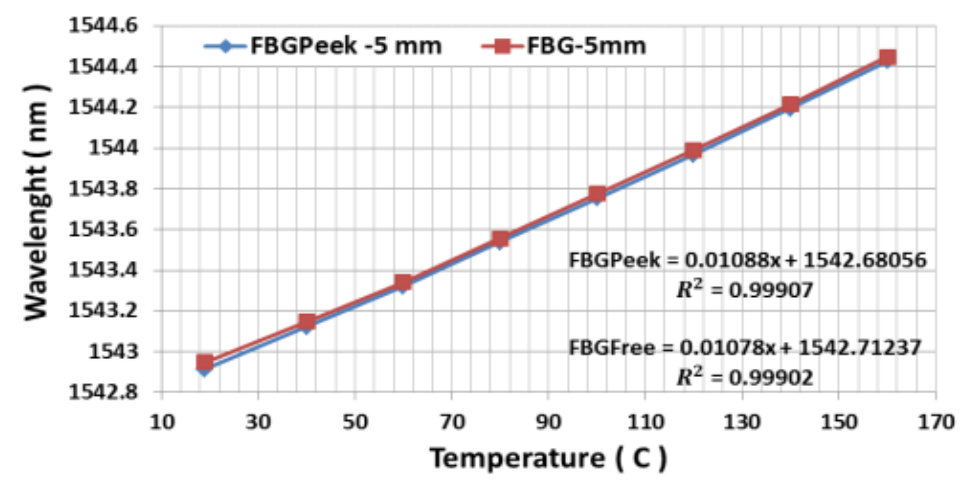

Figure 4. Calibration characteristics of the packaged and the bare FBG head. 
Once the operational implications of the packaged FBG sensor's motorette installation process have been understood the dynamic response of the in-situ sensor was characterised in a series of uniform $\approx 20^{\circ} \mathrm{C}$ step tests in the thermal chamber for the temperature range of $\approx 20^{\circ} \mathrm{C}$ to $\approx 160^{\circ} \mathrm{C}$. For illustration purposes the wavelength readings obtained from the FBG sensor were compared with temperature readings taken by an adjoining TC sensor, as shown in Fig. 6a-b. The measurements clearly illustrate that the measured Bragg wavelength change exhibits a closely similar response profile to that of the TC temperature measurement. However, while the TC thermal measurements report a series of uniform $20^{\circ} \mathrm{C}$ steps, the corresponding measured FBG sensor wavelength change is seen to comprise of a series of non-uniform steps; this phenomenon is directly related to the temperature sensitivity trends observed in Fig. 5b and illustrates the importance of appropriate calibration of the motorette embedded FBG sensor package. For this purpose, a secondorder polynomial quadratic fit of the measured wavelength and the corresponding temperature for the packaged FBG (shown in Fig. 4) was calculated and utilised to enable accurate temperature measurement from the recorded wavelength.

Finally the thermal monitoring performance of the motorette embedded packaged FBG sensor was evaluated in dynamic tests in the thermal chamber. The motorette was exposed to three thermal cycles from $\approx 20^{\circ} \mathrm{C}$ to $\approx 150^{\circ} \mathrm{C}$. Fig. 7 shows the obtained experimental results for the synchronously recorded FBG sensor and TC temperature measurements. To enable the assessment of steady-state thermal monitoring performance the chamber temperature was initially controlled to match the ambient temperature $\left(\approx 20^{\circ} \mathrm{C}\right)$ for the duration of $100 \mathrm{sec}$ before initiating thermal cycling for $\approx 30$ minutes. The applied thermal cycle is random in nature to represent arbitrary field operating conditions. The measured data show a good agreement between the temperature profiles recorded by the FBG and the TC sensors. The packaged FBG shows good repeatability with no significant evidence of hysteresis at this range of temperature and dynamic change rate [19].

The embedded FBG sensors response time is compared with that of the adjacent TC in a detailed view of the temperature change measured during the performed thermal cycle, shown in Fig. 8a. For the investigated thermal cycle dynamics the FBG is seen to deliver a closely identical response time to the TC. A detailed view of the thermal measurements taken during the initial steady-state thermal conditions is shown in Fig. $8 \mathrm{~b}$ to provide a comparison of TC and FBG steady-state performance. The results show that the TC and FBG recorded data are in close agreement with the maximum deviation between the measurements of $\approx 0.4^{\circ} \mathrm{C}$ and maximum deviation during cycle time of $\approx 1.5^{\circ} \mathrm{C}$.

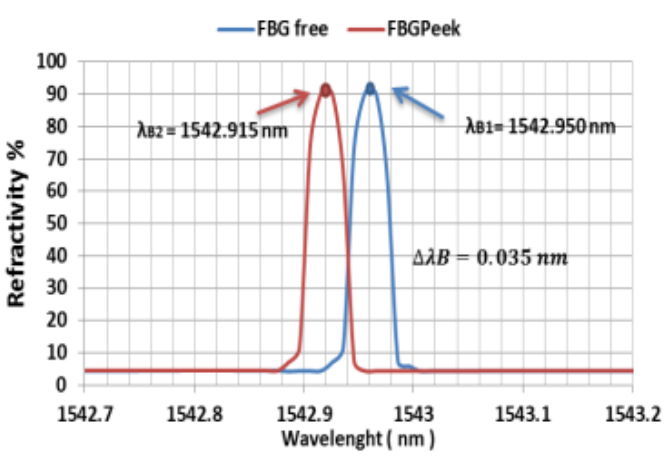

(a)

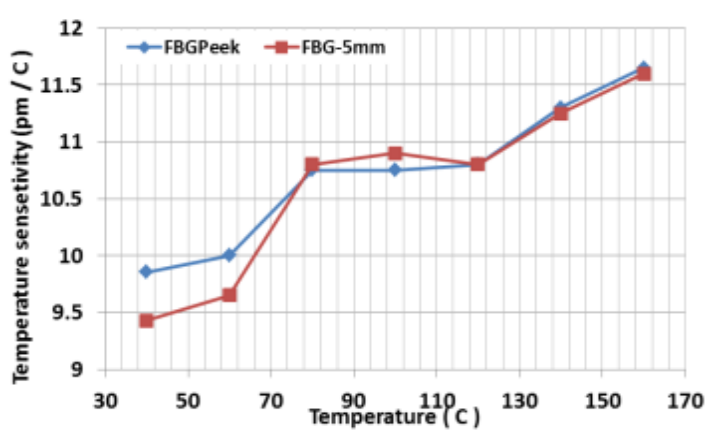

(b)

Figure 5. (a) Reflection spectrum of FBG before and after embedding

(b) Measured temperature sensitivity in the examined thermal range.

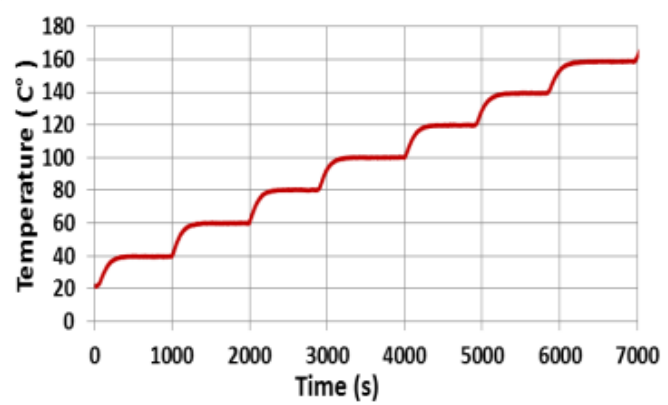

(a)

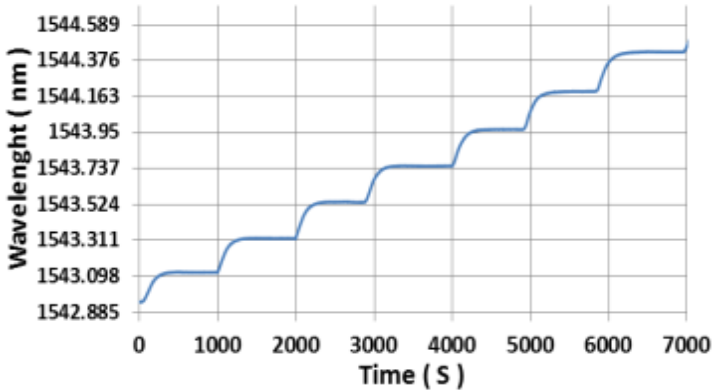

(b)

Figure 6. (a) TC thermal measurement during the calibration test,

(b) Corresponding FBGPeek wavelength dynamic response 


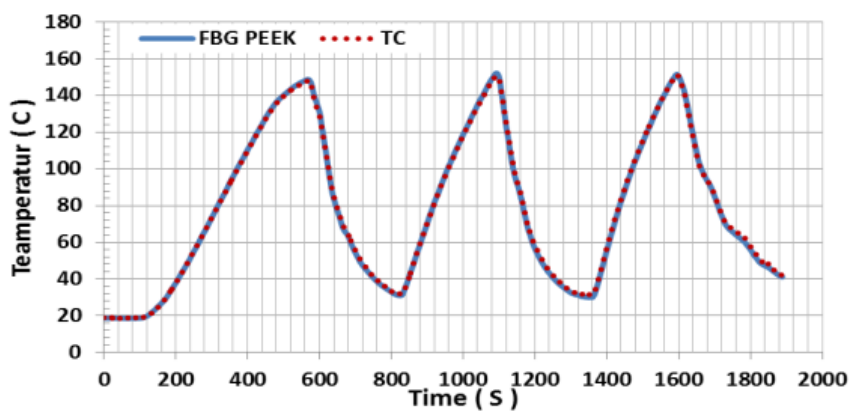

Figure 7. FBGPeek and TC thermal cycle measurements

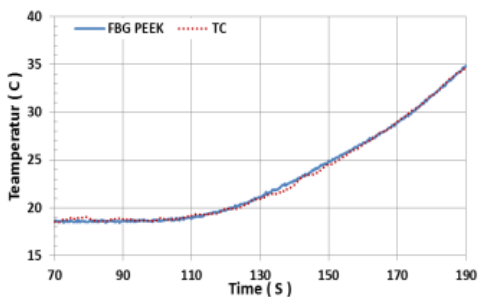

(a)

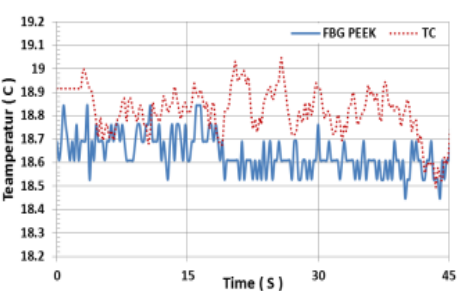

(b)

Figure 8. (a) FBGPeek and TC thermal response measurement, (b). FBGPeek and TC static thermal measurement

\section{CONCLUSIONS}

This work reports a performance assessment of a dielectric packaged FBG sensor use for thermal monitoring of hot spot temperature in random wound electric coils. The sensor package design is first presented, before reporting the results of an experimental study of the performance implications of the process of embedding the FBG sensing package into the physical structure of a test random wound coil. It is shown that, while sensor placement within the wound coil structure does result in some alteration of sensing characteristics, the sensing performance remains largely unaffected. The potential of the embedded FBG package to enable thermal hot spot temperature monitoring is examined in a range of experiments on a test coil under controlled static and dynamic thermal conditions. The FBG package sensing performance is validated by conventional TC sensors and shown to manifest good linearity and sensitivity. The reported results demonstrate that the presented FBG sensor design can reliably measure hot spot thermal conditions in a random wound electric coil and provide a useful precursor to informing further applications in wound components of operational electric machinery.

\section{REFERENCES}

[1] P.J. Tavner, "Review of condition monitoring of rotating electrical machines," in Electric Power Applications, IET, vol.2, no.4, July 2008.

[2] C.J. Crabtree, S. Djurovic, P.J. Tavner and A.C. Smith, "Condition monitoring of a wind turbine DFIG by current or power analysis," in Power Electronics, Machines and Drives (PEMD 2010), $5^{\text {th }}$ IET International Conference on, vol., no., pp.1-6, 19-21 April 2010.

[3] S. Djurovic, D. Vilchis-Rodriguez, and A.C., Smith, "Investigation of wound rotor induction machine vibration signal under stator electrical fault conditions," The IET Journal of Engineering, pp. 1-11, May 2014.

[4] P. M. Tuohy, S. Djurović and A. C. Smith, "Finite element analysis of winding fault effects in a wound-rotor induction machine with experimental validation" in Power Electronics, Machines and Drives (PEMD 2012), $6^{\text {th }}$ IET International Conference on, Bristol, 2012, pp. 1-

[5] S. Grubic, J.M Aller, Lu. Bin and T.G Habetler, "A Survey on testing and monitoring methods for stator insulation systems of low-voltage induction machines focusing on turn insulation problems," in Industrial Electronics, IEEE Trans. on, vol.55, no.12, pp.4127-36, Dec. 2008.
[6] P. Tavner, Li Ran and J. Penman, "Condition monitoring of rotating electrical machines," IET Power and Energy Series, 2008.

[7] A. Siddique, GS. Yadava, and B. Singh, "A review of stator fault monitoring techniques of induction motors," Energy conversion, IEEE transactions on 20.1 (2005): 106-114.

[8] L. Hoffmann, MS. Müller, S. Krämer, M. Giebel, G. Schwotzer, and T. Wieduwilt, "Applications of fibre optic temperature measurement." Proc. Estonian Acad. Sci. Eng 13, no. 4 (2007): 363-378.

[9] C. Martelli, E. Silva, K. Souza, F. Mezzadri, J. Somenzi, M. Crespin, H.J. Kalinowski, and J.C. Silva, "Temperature sensing in a $175 \mathrm{MW}$ power generator," Proc. SPIE 8421, OFS2012 22nd International Conference on Optical Fiber Sensors.

[10] K. Sousa, A. Hafner, M Crespim, V. Oliveira, H. Kalinoski and J. Silva, "Fiber Bragg grating sensing applications in temperature monitoring of three-phase induction motors," Microwave \& Optoelectronics Conference (IMOC), SBMO/IEEE MTT-S International. IEEE, 2011.

[11] D. Vilchis-Rodriguez, S. Djurovic, P. Kung, M.I Comanici, and A.C Smith, "Investigation of induction generator wide band vibration monitoring using fibre Bragg grating accelerometers," in Electrical Machines (ICEM), 2014 International Conference on, pp.1772-1778.

[12] D.S. Vilchis-Rodriguez, S. Djurovic , P. Kung , M. I. Comanici ; S. Scepanovic; K. Tshiloz; A. C. Smith, "Wide band fiber Bragg grating accelerometer for rotating AC machinery condition monitoring," Proc. SPIE Vol. 9288, Photonics North 2014, pp.1-10, September 25, 2014.

[13] M. Willsch, T. Bosselmann, M. Villnow and W. Ecke, "Fiber optical sensor trends in the energy field," Proc. SPIE 8421, OFS2012 22nd International Conference on Optical Fiber Sensors, 2012.

[14] A. D. Kersey, M. A. Davis, H. J. Patrick, M. LeBlanc, K. P. Koo, C. G. Askins, M. A. Putnam, and E. J. Friebele, "Fiber grating sensors." Journal of lightwave technology 15, no. 8 (1997): 1442-1463.

[15] Rao, Yun-Jiang, "In-fibre Bragg grating sensors," Measurement science and technology 8.4 (1997): 355.

[16] M. Reddy, "Characterization of encapsulating materials for fiber bragg grating-based temperature sensors." Fiber and Integrated Optics 33, no. 4 (2014): 325-335.

[17] IEEE Standard Test Procedure for Evaluation of Systems of Insulating Materials for Random-Wound AC Electric Machinery," in ANSI C50.32-1976 and IEEE Std 117-1974.

[18] https://www.smartfibres.com/FBG-interrogators.

[19] D. Barrera, V. Finazzi, J. Villatoro, "Packaged optical sensors based on regenerated fiber Bragg gratings for high temperature applications." Sensors Journal, IEEE 12.1 (2012): 107-112. 